\title{
Antibiotic Allergy, When to Test, Challenge or Desensitise
}

Iman Nasr ${ }^{1}$, Humaid A Al Wahshi ${ }^{2}$, Aisha A Al Wahshi ${ }^{3}$, Joanna Lukawska ${ }^{*}$

${ }^{1}$ Specialist in Immunology and Allergy, Royal Hospital, Oman

${ }^{2}$ Senior Consultant in Rheumatology, Immunology and maternal medicine, Royal Hospital, Oman

${ }^{3}$ Medical Student, Oman Medical College, Oman

${ }^{4}$ Consultant in Allergy, Department of Allergy, University college London Hospital, UK

*Corresponding author: Joanna Lukawska, Consultant in Allergy, Department of Allergy, University college London Hospital, UK, Tel: 44207377 7000; E-mail: joanna.lukawska@uclh.nhs.uk

Rec Date: Feb 02 2016; Acc Date: Jun 29 2016; Pub Date: Jul 042016

Copyright: (C) 2016 Nasr I, et al. This is an open-access article distributed under the terms of the Creative Commons Attribution License, which permits unrestricted use, distribution, and reproduction in any medium, provided the original author and source are credited.

\begin{abstract}
Antibiotics are widely used for treatment of bacterial infections and for prophylaxis during instrumental procedures and in certain conditions such as immunodeficiency and splenectomy.

Hypersensitivity (allergic) reactions are unpredictable and can occur in some patients even if they have taken the antibiotic in the past with no reaction. Drug allergy accounts for $11.3 \%$ of all adverse drug reactions. Drug allergy drugs can be generally classified (according to the World Allergy Organization) based on timing of symptoms into immediate (Immunoglobulin E (IgE) mediated) occurring within 1 hour and delayed (non IgE mediated) allergic reactions occurring after 1 hour. Many patients are mislabeled with drug allergy especially when the diagnosis is made based on history alone. In such cases, a referral to an allergist is important to confirm or exclude allergy through a detailed clinical history, in vitro and/or in vivo testing, as over diagnosis of drug allergy leads to the unnecessary use of broader spectrum and expensive antibiotics contributing to the emergence of multidrug resistant pathogens. Also, in cases of confirmed drug allergy it is important to establish potential cross reactivity with other drugs. Equally, patients with confirmed drug allergy, who have an absolute requirement for the drug or cross reactive drug (as in penicillin allergic females with syphilis) can undergo a process of desensitization in order to complete their treatment through induction of temporary tolerance of the drug.
\end{abstract}

Keywords: Antibiotic; Allergy; Skin testing; Challenge; Desensitization

\section{Introduction}

Hypersensitivity (allergic) reactions are unpredictable and can occur in some patients even if they have taken the antibiotic in the past with no reaction. Drug allergy accounts for $11.3 \%$ of all adverse drug reactions [1]. Many patients are mislabelled with drug allergy especially when the diagnosis is made based on history alone. Often the clinical history is not clear, for example, non-specific rash with penicillin in childhood or symptoms such as nausea and vomiting that are more likely to be related to drug side effects rather than allergy. In such cases, a referral to an allergist is important to confirm or exclude allergy, as over diagnosis of drug allergy leads to the unnecessary use of broader spectrum and expensive antibiotics contributing to the emergence of multidrug resistant pathogens [2]. Equally, under diagnosis of antibiotic allergy can have serious and sometimes fatal consequences [3]. In cases of confirmed drug allergy it is important to establish potential cross reactivity with other drugs (for example penicillins and cephalosporins).

Also, patients with confirmed drug allergy, who have an absolute requirement for the drug or cross reactive drug (as in penicillin allergic females with syphilis) can undergo a process of desensitization in order to complete their treatment through induction of temporary tolerance of the drug.
We will discuss the process of drug allergy testing and desensitization to familiarize the microbiologist and infectious disease specialist with this field of drug allergy.

\section{Epidemiology}

Drug allergy accounts for $11.3 \%$ of all adverse drug reaction [1]. Betalactams antibiotics are the most frequent drugs that cause allergic reactions $[4,5]$. The prevalence of beta-lactam allergy in the general population, based on patients' reports, ranges between 1\%-10\% [6], but only $10 \%-20 \%$ of patients suspected of beta-lactam allergy test positive on skin testing [7].

In a survey from the Boston Collaborative Drug Surveillance Program, the analysis of the incidence of cutaneous drug reactions in 15,438 hospitalized patients who received various antibiotics demonstrated 358 reactions reported and confirmed by a dermatologist with an overall frequency of $2.3 \%$. The number of reactions over the number of administrations for each drug was reported as $5.1 \%$ for amoxicillin, $3.4 \%$ for cotrimoxazole, $3.3 \%$ for ampicillin, $2.1 \%$ for cephalosporins, $2 \%$ for erythromycin, $1.8 \%$ for penicillin $\mathrm{G}$ and $0.4 \%$ for gentamicin [8].

\section{Types of Allergic Reactions}

Hypersensitivity (or allergic) reactions to drugs can be generally classified (according to the World Allergy Organization) based on timing of symptoms into immediate (Immunoglobulin E (IgE) 
mediated) and delayed (non IgE mediated) allergic reactions [9]. In most cases clinical history based on the timing of the drug reaction as well as signs and symptoms is able to establish this basic differential. In turn, this (IgE versus non IgE reactions) guides further testing and drug challenge (drug provocation) (Figure 1).

Immediate reactions (IgE) occur within 1 hour of exposure to the drug, whereas delayed reactions begin after 1 hour of exposure (usually between 6 hours to weeks) and are caused by other, non IgE mediated mechanisms [9].

In IgE mediated reactions (also known as Type I reactions), drug specific IgE forms upon exposure to that drug and causes mast cells and basophils to release vasoactive mediators. These cause signs and symptoms involving the skin and mucous membranes such as rash, itching and angioedema; respiratory system including chest tightness, difficulty in breathing, wheeze and stridor; gastrointestinal symptoms such as abdominal pain, diarrhoea and vomiting and cardiovascular system including tachycardia and hypotension. These should be differentiated from non-allergic symptoms such as isolated gastrointestinal upset and idiosyncratic reactions (for example, headache) as well as non IgE mediated such as maculopapular exanthema [10].

Non IgE mediated reactions (delayed reactions) generally appear after one hour and sometimes after days or weeks of treatment. Symptoms may also occur days after cessation of treatment and can pose a diagnostic challenge. These reactions are not mediated through IgE but through other immunologic mechanisms such as antibody (usually immunoglobulin G IgG)- mediated cell destruction in drug induced hemolytic anemia and thrombocytopenia (also called Type II reaction); antigen-antibody complex formation (Serum sickness, vasculitis, drug fever) (Type III reactions) and T cells activation as in Steven Johnson syndrome (SJS), toxic epidermal necrolysis (TEN), drug hypersensitivity with eosinophilia and systemic symptoms (DRESS) and contact dermatitis (Type IV reactions). Penicillin is an example of an antibiotic that can cause all types of reactions.

$\mathrm{T}$ cell mediated reactions (Type IV reactions) occur at least 48-72 hours to weeks following exposure to the index drug. They are generally the most prevalent type of reaction. T cells are stimulated by drugs by three main processes [11] which include the drug's ability to act as a hapten, a prohapten or to bind covalently to immune receptors (Pi concept). Haptens are small compounds $(<1000$ daltons) that are chemically reactive and bind to proteins or peptides and modify them convalently leading to stimulation of the innate immune system and resulting in neoantigens capable of stimulating $\mathrm{T}$ cells. On the other hand, Prohaptens are not chemically reactive and cannot form a covalent bond with a peptide unless converted into a hapten by being metabolized into a chemically reactive compound.

Lastly, in the Pi concept (pharmacologic interaction with immune receptors concept), although the chemically inactive drug is unable to covalently bind to proteins, it is able to reversibly interact with some of the immune receptors which under certain circumstances, can activate immune cells which then expand and cause inflammatory reactions of different types [11].

$\mathrm{T}$ cell mediated reactions can be tested by intradermal testing with delayed cutaneous reading and patch testing [12].

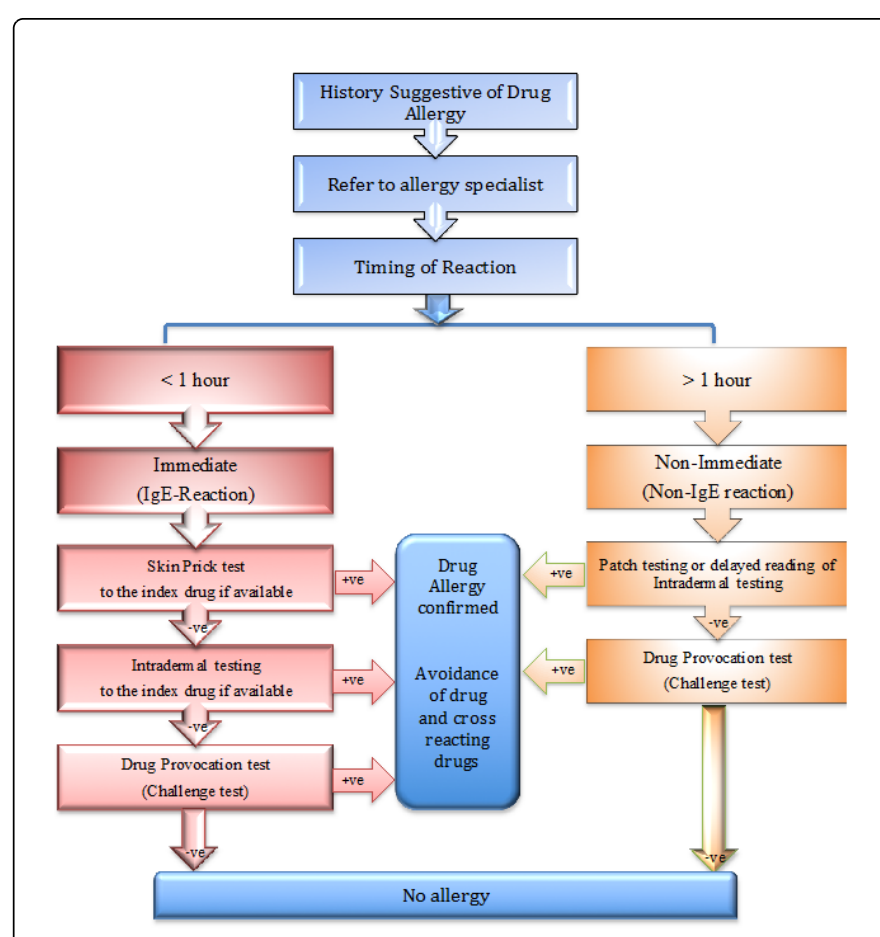

Figure 1: Diagnostic work up of drug allergy (IgE: Immunoglobulin $\mathrm{E},+$ ve: Positive, -ve: negative).

\section{Risk Factors for Drug Allergy}

Risk factors for allergic drug reaction can be divided into drug related factors and host related factors. The ability of the drug to act as a hapten, a prohapten or to bind convalently to immune receptors makes it immunogenic which explains why certain classes of drugs are more likely to cause drug allergies than others [13]. Allergic drug reactions are more likely to occur if there was a prior history of drug allergy as well as recurrent drug exposure. Cross-sensitization is another important drug factor that should be considered. Once sensitization to a drug has occurred, there is a possibility of reactivity either to drugs with chemically similar structures or to immunochemically similar metabolites.

Regarding host factors and for unclear reasons, female sex is thought to be a risk factor for allergic reactions to some drugs such as neuromuscular blockers, however, this does not apply to penicillins. Children seem to have a lower incidence of drug allergy probably because they are less likely exposed repeatedly to drugs. However, this risk increases with the frequent prescription of antibiotics in children with chronic disease such as cystic fibrosis [14]. Drug allergy in elderly hospitalized patients appears to be similar to the non-elderly, but serious reactions (anaphylaxis, SJS, TEN, DiHS) are less common [15]. Certain diseases carry risk of developing allergic reactions. These include the acquired immunodeficiency syndrome with increased rates of skin reactions to sulphonamides, abacavir and nevirapine caused by the inflammatory mediators released as a result of the Human immunodeficiency virus (HIV) [16,17]. Other diseases are EpsteinBarr virus (EBV) infection and leukemia [18]. Genetic factors appear to play in role in the predisposition of drug allergy. Certain HLA types such as HLA-B ${ }^{\star}$ 13:01 and the dapsone hypersensitivity syndrome [19], 
HLA B ${ }^{\star} 1502$ associated with carbamazepine induced SJS/TEN in Han Chinese in Taiwan and Indians [20-22] and HLA $A^{*} 31: 01$ in Japanese and Europeans $[23,24]$.

\section{Diagnosis}

It is important to start with a detailed drug and index event history. When the history is strongly suggestive of an allergic reaction to the drug in question, the diagnosis can be based on history alone and further testing can be avoided. However, when the history is poor or when multiple drugs are involved such as during general anesthesia, it is essential to establish the culprit drug through in vitro or proceed to in vivo drug testing performed by skin testing and when necessary through graded drug provocation test (DPT) also known as drug challenge.

Drug testing should be avoided if the reaction was very severe and involved bullous or exfoliative skin dermatoses such as: Steven Johnson syndrome and Toxic Epidermal Necrolysis. These patients should avoid the index drug for life.

\section{In Vivo Testing}

\section{Skin testing}

Generally, skin testing for IgE mediated reactions involves two methods, skin prick test (SPT) and intradermal test (ID). Skin prick testing detects the presence of drug specific IgE in the skin and can therefore predict only the likelihood of IgE mediated drug allergy [25]. It is not useful for identifying other types of reactions. Skin prick testing is more specific, but less sensitive than intradermal testing and should precede it. Skin prick testing is always performed before intradermal testing and severe systemic reactions can occur even at this stage [26]. Histamine and normal saline is used as positive and negative control respectively for the test. Histamine is not used intradermally. A drop of antigen is placed on the forearm and a lancet is inserted at $45 \%$ to lift the epidermis. The skin is observed for $10-15$ minutes. A positive reaction is defined as a wheal and flare, with the diameter of the wheal measuring at least $3 \mathrm{~mm}$ more than the negative control. If SPT is negative, intradermal test is performed with a 30 gauge needle where $0.02-0.03 \mathrm{~mL}$ of antigen solution is injected into the dermis of the skin in order to create a small bleb. This can be marked with a pen. The skin is then observed for 15-20 minutes and any reaction rated as positive or negative. A positive reaction is defined as a wheal and flare, with the diameter of the wheal measuring at least $3 \mathrm{~mm}$ more than the negative control (Figure 2). Some drugs such as antihistamines can give rise to a false negative skin testing and therefore, should be stopped at least 48 hours prior to the test. In certain cases ID testing can be used for non IgE mediated drug reactions [12]. It is performed using commercially prepared, nonirritant injectable form of the drug in the same way as described above. The site is examined after $24-48$ hours with a positive result as described above [12]

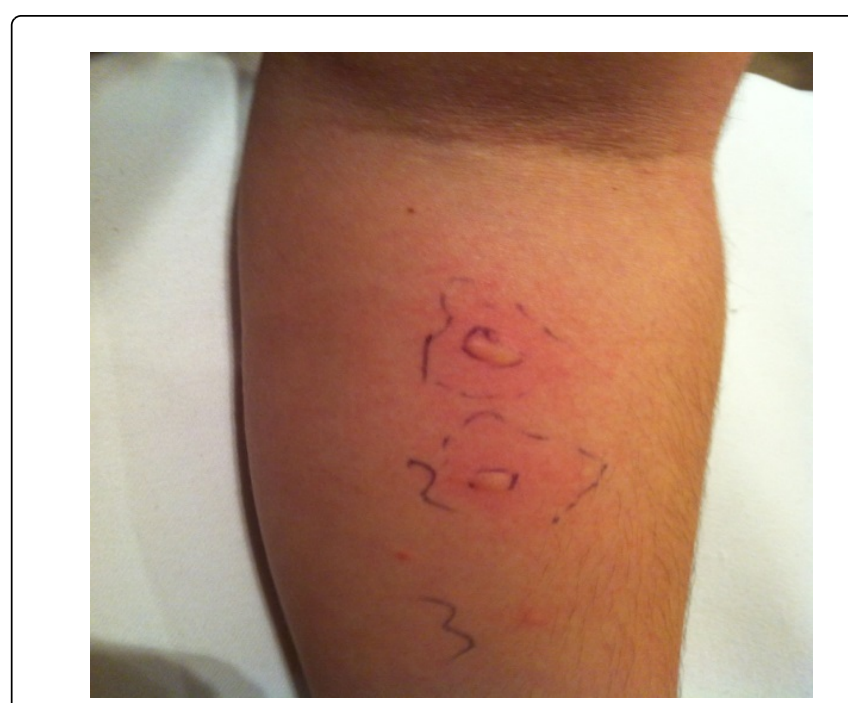

Figure 2: Positive skin prick test to Amoxicillin (1st upper) and Co Amoxyclav (2nd upper) defined as a wheal and flare. Negative to Cefuroxime (lower).

Patch testing is also used to evaluate non $\operatorname{IgE}$ mediated drug reactions. This is done using certain concentration of a drug mixed into petroleum or $0.9 \%$ saline and applied to a small area of skin covered for 48 hours. This is then removed and the area examined 48-96 hours from the start of the test [12].

\section{Drug provocation test (DPT)}

When skin testing is negative or not available, DPT is performed cautiously by a trained and experienced allergist and in a hospital setting where resuscitation facilities are available. The route of administration depends on the index drug (oral, intravenous, subcutaneous or intramuscular). Prior to the challenge, patients should stop antihistamines for at least 72 hours as these may mask early signs of an allergic reaction. Beta-blockers should not be taken for at least 24 hours before the challenge if possible as they can interfere with treatment of potential anaphylaxis. The risk of severe anaphylaxis during DPT is mitigated by reintroduction of the investigated drug at a very small dose (usually $1 / 100$ the total dose), then increasing it incrementally every 30 minutes, provided no objective signs of allergic reaction occur, until the full therapeutic dose is received. The patient is observed for 1 hour following the last dose. Table 1 for an example of an oral challenge for amoxicillin.

\begin{tabular}{|l|l|l|}
\hline Step & Time interval & Dose \\
\hline 1st dose of amoxicillin & 30 minutes & $5 \mathrm{mg}$ \\
\hline 2nd dose of amoxicillin & 30 minutes & $50 \mathrm{mg}$ \\
\hline 3rd dose of amoxicillin & 30 minutes & $250 \mathrm{mg}$ \\
\hline 4th dose of amoxicillin & 30 minutes & $500 \mathrm{mg}$ \\
\hline
\end{tabular}

Table 1: Example of oral challenge for amoxicillin. 
Page 4 of 7

Patients with positive skin tests or positive DPT to the index drug should avoid it for life. Both diagnostic methods can also be used to look for drug crossreactivity.

For example, in case of allergy to penicillin, drugs such as cephalosporins may be tolerated provided cephalosporin skin testing and challenge are negative.

\section{In Vitro Testing}

Allergen-specific IgE levels are measured by either radioallergosorbent tests (RASTs) or radioimmunoassay (RIA) commercially available as ImmunoCAP ${ }^{\star}$, enzyme linked immunosorbent assay (ELISA) or fluoroenzyme immunoassay (FEIA) [27]. These tests detect the presence of serum IgE antibodies against some antibiotics including penicilloyl, amoxicilloyl, ampicilloyl and cefaclor. It is not affected by antihistamines and although the specificity is close to $100 \%[28,29]$, they lack sensitivity compared to clinical history and skin tests and a negative result cannot exclude allergy. Although most UK allergy centers perform specific IgE to pencillins, its use in clinical practice is highly varied [30].

The basophil activation test (BAT) is a method of measuring druginduced activation of basophils using flow cytometry that measures alterations in the cell surface expression of basophil activation markers, such as CD63 or CD203 [31].

BAT is not routinely used in clinical practice at present. It has been studied in a limited number of drugs. Although it has a good specificity, the sensitivity for drug allergies is low. It is of use when skin testing and specific IgE testing results are equivocal. It is possible to examine for potential cross reactivity with related drugs [32]. For betalactam antibiotics, the reported sensitivity varies between $22 \%$ and $55 \%$, and specificity between $79 \%$ and $100 \%$ [31].

The lymphocyte transformation test (LTT) has been shown to be useful in the diagnosis of T-cell mediated delayed hypersensitivity reactions with a variety of drugs [27]. Lymphocytes isolated from peripheral blood mononuclear cells (PBMCs) of a patient with a specific delayed hypersensitivity reaction are cultured with pharmacologic concentrations of the drug in question and then stimulated after 5-7 days. Enhanced proliferative responses in the presence of a drug are considered positive for that drug-specific T-cell sensitisation.

Although a positive LTT is useful in confirming the diagnosis, a negative test does not exclude drug hypersensitivity. Positive LTT are usually drug-specific, and reaction-specific. The sensitivity of the LTT varies widely between studies, is related to both the drug and phenotype of clinical reaction and is still considered a research method [33].

\section{Desensitization}

In some cases where the patient is allergic to an antibiotic and no other alternative is available such as pregnant females with syphilis who are penicillin allergic, or when the drug in question is more effective than the alternative, a process known as desensitization can be performed.

Drug desensitization involves administration of incrementally increasing doses of the drug in order to induce temporary tolerance and hence allow the patient to take the medication safely. It is effective for as long as the patient is receiving the drug in question. Once the drug is discontinued, the patient's allergy to that drug returns. This is performed in a specialized allergy center, in a hospital setting with all resuscitation facilities available in case of anaphylaxis. Desensitization should not be performed in patients with severe exfoliative reactions such as SJS or TNE. Table 2 for indications and contraindications to performing desensitization.

\begin{tabular}{|l|l|}
\hline Indications for Desensitisation & Contraindications to Desensitisation \\
\hline $\begin{array}{l}\text { Drug in question is irreplaceable (penicillin and syphilis in pregnancy, carboplatin in } \\
\text { ovarian cancer) }\end{array}$ & Severe, life threatening immunocytotoxic reactions \\
\hline $\begin{array}{l}\text { Drug in question is more effective than alternatives } \\
\text {-Antibiotics in Cystic fibrosis or HIV }\end{array}$ & Vasculitis \\
\hline -Aspirin in cardiovascular disease or in aspirin exacerbated respiratory disease & Bullous skin diseases \\
\hline & (SJS, TEN, DRESS) \\
\cline { 2 - 3 } & Interstitial nephritis \\
\cline { 2 - 2 } & Hepatitis \\
\cline { 2 - 3 } & Haemolytic anaemia \\
\hline
\end{tabular}

Table 2: Indications and contraindications to desensitization.

Desensitization can be performed by oral, intravenous, or subcutaneous routes. The oral route is the safest, and is used whenever possible. The first dose is usually $1 / 10000000$ to $1 / 10000$ of the normal dose. This is doubled every 15-30 minutes until the full dose is reached (usually in 12-15 steps). Allergic reactions may occur in around $25 \%$ of patients undergoing the process of desensitization (authors unpublished data) [34]. However, no fatal reactions have been reported so far. Desensitisations have been performed safely in pregnant women [35]. Table 3 for an example of desensitization for amoxicillin.

There is some confusion amongst the medical community as to the difference between drug challenge and drug desensitization. Table 4 where we have summarized both processes. 


\section{Summary}

Majority of hospital inpatients require antibiotics during their admission [36]. It is therefore hardly surprising that antibiotics now account for the highest expenditure of all categories of medicinal products constituting $19 \%$ of the total expenditure on medicines in secondary care [37]. Antibiotic-associated adverse reactions are a significant public health care problem worldwide [2,38]. Leading to prolonged hospitalisation, antibiotic resistance, poorer health outcomes and increased cost [39]. Collaboration with allergists and antibiotic drug allergy assessment are fundamental to any successful antibiotic stewardship programme.

\section{Keypoints}

- Many patients who have been labelled with drug allergy may be able to tolerate the drug in question.
- Patients who have a requirement for the "allergen drug" or are likely to require it in the future should be referred to the drug allergy service.

- Delayed intradermal skin testing may be useful in evaluating delayed drug reactions, however, it is not diagnostic and when appropriate it should be followed by cautious drug reintroduction.

- The process of DPT for immediate, IgE mediated drug reactions differs from the process of drug reintroduction in case of delayed, non IgE mediated drug reactions.

- Patients with proven allergy and an absolute requirement for the drug may undergo desensitization process in order to achieve temporary tolerance to the drug (this is different to the challenge process).

- At present there is no evidence for efficacy of desensitization in delayed, non IgE mediated drug reactions.

\begin{tabular}{|c|c|c|c|c|c|c|}
\hline Step & Time $(\min )$ & Time cumulative $(\min )$ & $\begin{array}{l}\text { Solution } \\
\text { (Concentration } \mathrm{mg} / \mathrm{mL} \text { ) }\end{array}$ & Amount (mL) & Dose mg & Cumulative dose \\
\hline 1 & 20 & 0 & $(0.1 \mathrm{mg} / \mathrm{mL})$ & 0.1 & 0.01 & 0.01 \\
\hline 2 & 20 & 20 & $(0.1 \mathrm{mg} / \mathrm{mL})$ & 0.2 & 0.02 & 0.03 \\
\hline 3 & 20 & 40 & $(0.1 \mathrm{mg} / \mathrm{mL})$ & 0.4 & 0.04 & 0.07 \\
\hline 4 & 20 & 60 & $(0.1 \mathrm{mg} / \mathrm{mL})$ & 0.8 & 0.08 & 0.15 \\
\hline 5 & 20 & 80 & $(0.1 \mathrm{mg} / \mathrm{mL})$ & 1.6 & 0.16 & 0.31 \\
\hline 6 & 20 & 100 & $(0.1 \mathrm{mg} / \mathrm{mL})$ & 3.2 & 0.32 & 0.63 \\
\hline 7 & 20 & 120 & $(0.1 \mathrm{mg} / \mathrm{mL})$ & 6.4 & 0.64 & 1.27 \\
\hline 8 & 20 & 140 & $(0.5 \mathrm{mg} / \mathrm{ml})$ & 2 & 1 & 2.27 \\
\hline 9 & 20 & 160 & $(0.5 \mathrm{mg} / \mathrm{ml})$ & 4 & 2 & 4.27 \\
\hline 10 & 20 & 180 & $(0.5 \mathrm{mg} / \mathrm{ml})$ & 8 & 4 & 8.27 \\
\hline 11 & 20 & 200 & $(5 \mathrm{mg} / \mathrm{ml})$ & 1.5 & 7.5 & 15.77 \\
\hline 12 & 20 & 220 & $(5 \mathrm{mg} / \mathrm{ml})$ & 3 & 15 & 30.77 \\
\hline 13 & 20 & 240 & $(5 \mathrm{mg} / \mathrm{ml})$ & 6 & 30 & 60.77 \\
\hline 14 & 20 & 260 & $(5 \mathrm{mg} / \mathrm{ml})$ & 12 & 60 & 120.77 \\
\hline 15 & 20 & 280 & Stock $(25 \mathrm{mg} / \mathrm{mL})$ & 5 & 125 & 245.77 \\
\hline \multicolumn{7}{|c|}{ Switch to tablet form } \\
\hline 16 & 20 & 300 & Tablet $250 \mathrm{mg}$ & 1 & 250 & 495.77 \\
\hline 17 & 20 & 320 & Tablet $250 \mathrm{mg}$ & 2 & 500 & 995.77 \\
\hline
\end{tabular}

Table 3: Amoxicillin Desensitisation Premedication 1 hour before with Cetirizine $10 \mathrm{mg}$ orally, Ranitidine $150 \mathrm{mg}$ orally, Montelukast $10 \mathrm{mg}$ orally. 


\begin{tabular}{|l|l|}
\hline Allergy-unproven & Allergy-proven \\
\hline Done to establish diagnosis & Done to produce temporary tolerance \\
\hline Start with $1 / 100-1 / 10$ therapeutic dose & Start with $1 / 1000000$ to $1 / 10000$ therapeutic dose \\
\hline In $3-5$ steps & In $12-13$ steps \\
\hline
\end{tabular}

Table 4: The difference between drug challenge and drug desensitisation.

\section{Disclosures:}

Non to disclose by all authors

\section{References}

1. Einarson TR (1993) Drug-related hospital admissions. Ann Pharmacother 27: 832-840.

2. Macy E, Contreras R (2014) Healthcare utilization and serious infection prevalence associated with penicillin "allergy" in hospitalized patients: a cohort study. J Allergy Clin Immunol 133: 790-796.

3. Pumphrey RS, Davis S (1999) Under-reporting of antibiotic anaphylaxis may put patients at risk. Lancet 353: 1157-1158.

4. Blanca M (1995) Allergic reactions to penicillins. A changing world? Allergy 50: 777-782.

5. Blanca M, Vega JM, Garcia J, Miranda A, carmona MJ, et al. (1994) New aspects of allergic reactions to beta-lactams: crossreactions and unique specificities. Clin Exp Allergy 24: 407-415.

6. Park MA, Li JT (2005) Diagnosis and management of penicillin allergy Mayo Clin Proc 80:405-410.

7. Mendelson LM (1998) Adverse reactions to beta-lactam antibiotics. Immunol Allergy Clin North Am 18:745-56.

8. Bigby M, Jick S, Jick H, Arndt K (1986) Drug-induced cutaneous reactions. A report from the Boston Collaborative Drug Surveillance Program on 15,438 consecutive inpatients, 1975 to 1982. JAMA 256: 3358-63.

9. Johansson SG, Bieber T, Dahl R, Friedmann PS, Lanier BQ, et al. (2004) Revised nomenclature for allergy for global use: Report of the 'nomenclature Review Committee of the World Allergy Organisation, October 2003. J Allergy Clin Immunol 113: 832-6.

10. Romano A, Blanca M, Torres MJ, Bircher A, Aberer W, et al. (2004) Diagnosis of nonimmediate reactions to beta-lactam antibiotics. Allergy 59: 1153-60.

11. Pichler WJ, Park BK, Naisbitt DJ (2011) Immune pathomechanism of drug hypersensitivity reactions. J Allergy Clin Immunol 127: S74-81.

12. Barbaud A (2009) Skin testing in delayed reactions to drugs. Immunol Allergy Clin North Am 29: 517-535.

13. Schneck J, Fagot JP, Sekula P, Sassolas B, Roujeau JC, et al. (2008) Effects of treatments on the mortality of Stevens-Johnson syndrome and toxic epidermal necrolysis: a retrospective study on patients included in the prospective EuroSCAR Study. J Am Acad Dermatol 58: 33-40.

14. Moss RB, Babin S, Hsu YP, Blessing-Moore J, Lewiston NJ (1984) Allergy to semisynthetic penicillins in cystic fibrosis. J Pediatr 104: 460-466.

15. Chng HH, Leong KP, Cheng YK, Tang CY, Chia FL, et al. (2008) Elderly inpatients have drug allergy manifestations and outcome similar to the non-elderly but serious reactions are less common: results of a 9-year prospective study. Allergy 63: 379 .

16. Phillips E, Mallal S (2007) Drug hypersensitivity in HIV. Curr Opin Allergy Clin Immunol 7: 324-330.

17. Avila PC, Kishiyama JL (1996) Allergic manifestations in AIDS. Clin Rev Allergy Immunol 14: 433-449.

18. Cameron SJ, Richmond J (1971) Ampicillin hypersensitivity in lymphatic leukemia. Scott Med J 16: 425-427.
19. Zhang FR, Liu H, Irwanto A, Fu XA, Li Y, et al. (2013) HLA-B ${ }^{\star} 13: 01$ and the dapsone hypersensitivity syndrome. N Engl J Med 369: 1620-1628.

20. Man CB, Kwan P, Baum L, Yu E, Lau KM, et al. (2007) Association between HLA-B ${ }^{\star} 1502$ allele and antiepileptic drug-induced cutaneous reactions in Han Chinese. Epilepsia 48: 1015-1018.

21. Locharernkul C, Loplumlert J, Limotai C, Korkij W, Desudchit T, et al. (2008) Carbamazepine and phenytoin induced Stevens-Johnson syndrome is associated with the HLA-B ${ }^{\star} 1502$ allele in a Thai population. Epilepsia 49: 2087-2091.

22. Mehta TY, Prajapati LM, Mittal B, Joshi CG, Sheth JJ, et al. (2009) Association of HLA-B ${ }^{\star} 1502$ allele and carbamazepine-induced StevensJohnson syndrome among Indians. Indian J Dermatol Venereol Leprol 75: 579-582.

23. Ozeki T, Mushiroda T, Yowang A, Takahashi A, Kubo M, et al. (2011) Genome-wide association study identifies HLA-A*3101 allele as a genetic risk factor for carbamazepine-induced cutaneous adverse drug reactions in Japanese population. Hum Mol Genet 20: 1034-1041.

24. McCormack M, Alfirevic A, Bourgeois S, Farrell JJ, Dalia Kasperavičiūtė MS, et al. (2011) HLA-A* 3101 and carbamazepine-induced hypersensitivity reactions in Europeans. N Engl J Med 364: 1134-1143.

25. Yates AB (2008) Management of patients with a history of allergy to betalactam antibiotics. Am J Med 121: 572-576.

26. Novembre E, Bernardini R, Bertini G, Massai G, Vierucci A (1995) Skinprick-test-induced anaphylaxis. Allergy 50: 511-3.

27. Gómez E, Torres MJ, Mayorga C, Blanca M (2012) Immunologic evaluation of drug allergy. Allergy Asthma Immunol Res 4: 251-263.

28. Mayorga C, Sanz ML, Gamboa PM, García BE, Caballero MT, et al. (2010) on behalf of the Clinical Immunology Committee of the Spanish Society of Allergology and Clinical Immunology of the SEAIC (2010). In vitro diagnosis of immediate allergic reactions to drugs: an update. J Investig Allergol Clin Immunol 20: 103-109.

29. Fontaine C, Mayorga C, Bousquet PJ, Arnoux B, Torres MJ, et al. (2007) Relevance of the determination of serum- specific IgE antibodies in the diagnosis of immediate beta-lactam allergy. Allergy 62: 47-52.

30. Richter AG, Nasser SM, Krishna MT (2013) A UK national survey of investigations for beta-lactam hypersensitivity - heterogeneity in practice and a need for national guidelines - on behalf of British Society for Allergy and Clinical Immunology (BSACI). Clin Exp Allergy 43: 941-949.

31. Leysen J, Sabato V, Verweij MM, De Knop KJ, Bridts CH, et al. (2011) The basophil activation test in the diagnosis of immediate drug hypersensitivity. Expert Rev Clin Immunol 7: 349-355.

32. Hausmann OV, Gentinetta T, Bridts CH, Ebo DG (2009) The basophil activation test in immediate-type drug allergy. Immunol Allergy Clin North Am 29: 555-566.

33. Nagao-Dias AT, Teixeira FM, Coelho HL (2009) Diagnosing immunemediated reactions to drugs. Allergol Immunopathol (Madr) 37: 98-104.

34. Castells M, Sancho-Serra M, Simaro M (2012) Hypersensitivity to antineoplastic agents: mechanisms and treatment with rapid desensitization. Cancer Immunol Immunother 61: 1575-1584.

35. Wendel GD Jr, Stark BJ, Jamison RB, Molina RD, Sullivan TJ (1985) Penicillin allergy and desensitization in serious infections during pregnancy. N Engl J Med 312: 1229-1232. 
Citation: Nasr I, Wahshi HAAI, Wahshi AAAI, Lukawska J (2016) Antibiotic Allergy, When to Test, Challenge or Desensitise. J Med Microb Diagn 5: 234. doi:10.4172/2161-0703.1000234

Page 7 of 7

36. Hulscher M, Grol R, van der Meer J (2010) Antibiotic prescribing in hospitals: a social and behavioural scientific approach. Lancet Infect Dis 10: $167-175$.

37. Curtis C, Marriott J, Langley C (2004) Development of a prescribing indicator for objective quantification of antibiotic usage in secondary care. J Antimicrob Chemother 54: 529-533.
38. Shehab N, Patel PR, Srinivasan A, Budnitz DS (2008) Emergency department visits for antibiotic-associated adverse events. Clin Infect Dis 47: 735-743.

39. Holtzer I, Levo Y, Kivity S (2003) The economic burden of antibiotic treatment of penicillin-allergic patients in internal medicine wards of a general tertiary care hospital. Clin Exp Allergy 33: 501-506. 